\title{
Tumor epitelial e estromal misto do rim: relato de caso
}

\section{Mixed epithelial and stromal tumor of the kidney: case report}

Francisco Flávio Barbosa ${ }^{1,2}$. Adriana Regina Vilarinho de Oliveira ${ }^{1}$. Emília Tomé de Sousa ${ }^{1}$. Carlos Gustavo Hirth $^{1,3}$.

1 Universidade Federal do Ceará (UFC), Fortaleza, Ceará, Brasil. 2 Laboratório Mikros, Fortaleza, Ceará, Brasil. 3 Instituto do Câncer do Ceará, Fortaleza, Ceará, Brasil.

\section{RESUMO}

O tumor epitelial e estromal misto do rim é uma neoplasia rara, caracterizada pelo seu padrão histopatológico bifásico, formado por elementos epiteliais e estromais. Predomina no sexo feminino, na perimenopausa e sua patogênese ainda é desconhecida. Relata-se o caso de uma paciente de 54 anos, que iniciou crises recorrentes de dor em flanco direito e disúria. Os exames de imagem evidenciaram lesão cística complexa em rim esquerdo e paciente foi submetida à nefrectomia. $\mathrm{O}$ exame histopatológico e a imuno-histoquímica confirmaram o diagnóstico.

Palavras-chave: Rim. Patologia. Neoplasias.

\section{ABSTRACT}

The mixed epithelial and stromal tumor of the kidney is a rare neoplasm, characterized by its biphasic histopathological pattern, formed by epithelial and stromal elements. It predominates in females, in perimenopause and its pathogenesis is still unknown. We report the case of a 54-year-old female patient who started recurrent bouts of right flank pain and dysuria. The imaging exams revealed complex cystic lesion in the left kidney and the patient underwent nephrectomy. Histopathological examination and immunohistochemistry confirmed the diagnosis.

Keywords: Kidney. Pathology. Neoplasias.

Autor correspondente: Francisco Flávio Barbosa, Avenida Augusto dos Anjos, 312, Joquei Clube, Fortaleza, Ceará. CEP: 60520-022. Telefone: +55 85 99763-8207. E-mail: fflaviob@hotmail.com

Conflito de interesses: Não há qualquer conflito de interesses por parte de qualquer um dos autores.

Recebido em: 25 Mai 2015; Revisado em: 06 Out 2018; Aceito em: 06 Out 2018. 


\section{INTRODUÇÃO}

O tumor epitelial e estromal misto do rim (MESTK) é uma neoplasia rara e complexa composta por uma mistura de elementos epiteliais embebidos em estroma de células fusiformes. ${ }^{1}$ Foi relatado inicialmente por Block et al em 1973, sendo originalmente considerado como nefroma mesoblástico congênito, ${ }^{2}$ mas foi apenas em 1998 que Michal e Syrucek o descreveram. ${ }^{3}$

Trata-se de um tumor benigno que acomete principalmente mulheres, sendo relatado uma média de seis casos femininos para cada caso masculino sobretudo de meia idade com história de terapia de reposição hormonal. ${ }^{4}$ Os sintomas costumam ser inespecíficos, podendo inclusive o quadro clínico ser assintomático. ${ }^{5}$

A neoplasia se apresenta como massa cística, em geral multilocular e unilateral. Imagenologicamente, é uma lesão complexa, podendo fazer diagnóstico diferencial com outras lesões renais císticas. Pode ser descoberta acidentalmente em ultrassonografias ou tomografias computadorizadas, realizadas para investigação de outras entidades nosológicas. ${ }^{6}$

Histologicamente, o MESTK é composto por dois componentes: epitelial, representado por cistos, microcistos e túbulos recobertos por células cuboidais ou colunares e estromal, que consiste de uma variável população de células fusiformes com núcleos ovoides e citoplasma amplo. As células estromais são compostas de fibroblastos, miofibroblastos e células musculares lisas em várias combinações. ${ }^{1}$

O tratamento costuma ser curativo com nefrectomia parcial ou total e não há história relatada na literatura de recorrência ou metástase. ${ }^{7,8}$

Diante disso, propõe-se neste artigo relatar um caso de tumor epitelial e estromal misto do rim diagnosticado em um paciente feminino no Hospital Universitário Walter Cantídio.

\section{RELATO DE CASO}

Paciente feminina, 54 anos, iniciou em 2015 crises recorrentes de dor em flanco direito e disúria. Procurou assistência médica sendo realizada ultrassonografia abdominal que evidenciou litíase renal à direita. Paciente foi encaminhada para acompanhamento no Hospital Universitário Walter Cantídio, onde realizou tomografia computadorizada multislice de abdome e pelve que demonstrou em rim esquerdo lesão expansiva cística de contornos lobulados com paredes e septações internas espessas, situada nos terços médio e superior do rim, projetando-se para a pelve renal e abaulando o contorno renal superiormente, medindo cerca de 7,6 x 4,7 x 4,0 cm nos maiores eixos e classificada como Bosniak 3; em rim direito foi visualizado cálculo coraliforme preenchendo parcialmente o sistema pielocalicial medindo cerca de 4,5 $\mathrm{cm}$ no seu maior eixo. Foram vistos também dois cistos corticais simples nos terços médios dos rins, medindo $0,8 \mathrm{~cm}$ cada (Bosniak 2). Paciente foi submetida à nefrolitotripsia percutânea e realizada nefrectomia esquerda, posteriormente.
Macroscopicamente, o rim apresentava lesão bem circunscrita em polo superior, medindo $7,0 \mathrm{~cm}$ no maior diâmetro, cística, com superfície externa pardacenta e lisa. Aos demais cortes, exibia áreas císticas com septos espessos e áreas sólidas.

À microscopia, os cortes histológicos mostravam neoplasia bifásica formada por cisto e microcistos, revestidos por epitélio cuboidal simples e túbulos com revestimento epitelial típico, além de proliferação de células fusiformes, entremeadas por fibras musculares, aprisionando túbulos e formando arranjos nodulares (Figura 1). O parênquima renal adjacente exibia glomérulos preservados e interstício com leve infiltrado inflamatório linfocítico. Ureter, artéria e veia renais não demonstravam alterações.

Foi realizado estudo imuno-histoquímico que mostrou positividade nos túbulos e cistos para citoceratina AE1/AE3 e CK7 e negatividade para CK20. O estroma foi positivo para os seguintes marcadores: alfa-actina, desmina, vimentina, RE e $\mathrm{RP}$, e o índice de proliferação medido pelo Ki-67 foi negativo, confirmando o diagnóstico de tumor epitelial e estromal misto do rim (Figuras 2, 3 e 4).

A paciente foi seguida clinicamente e não foram evidenciadas metástases ou recorrência da doença.

Figura 1. Microfotografia exibindo ductos em meio a estroma de células fusiformes (HE 100x).

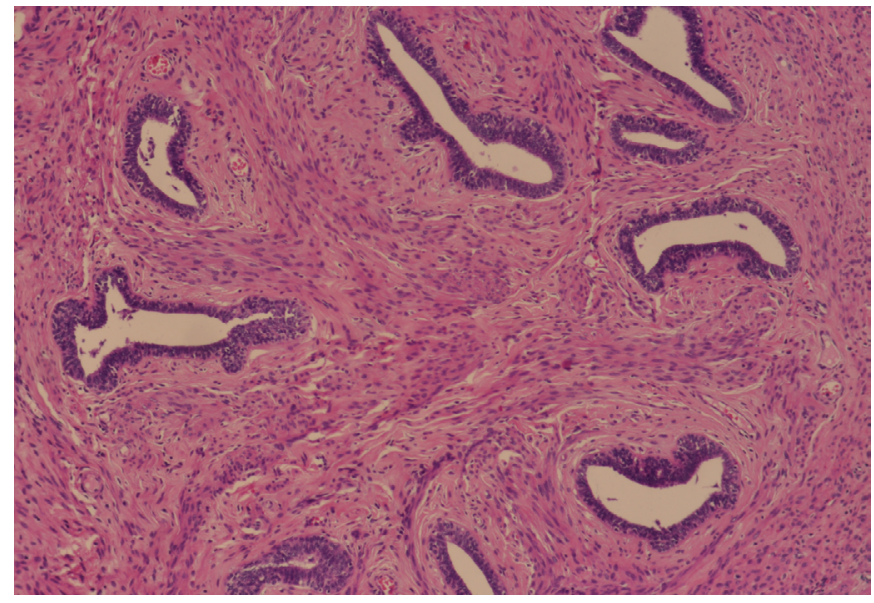

Figura 2. Marcadores epiteliais e índice de proliferação. A) Imunoexpressão de CK7 (100x); B) Imunoexpressão de CK AE1/ AE3 (100x).

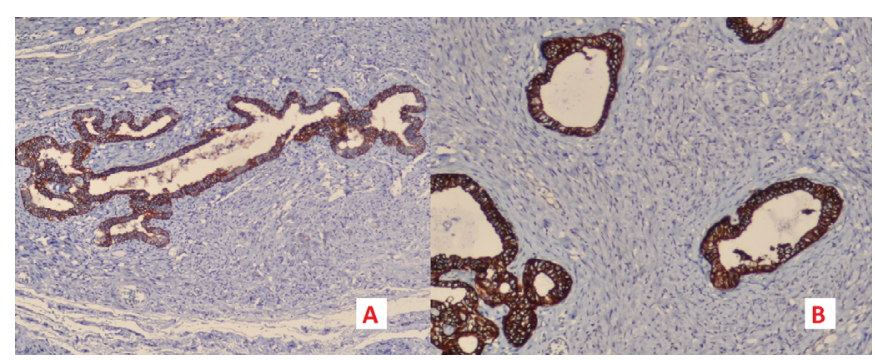


Figura 2. Marcadores epiteliais e índice de proliferação. C) Imunonegatividade para CK20 (100x); D) Ki-67 (100x).

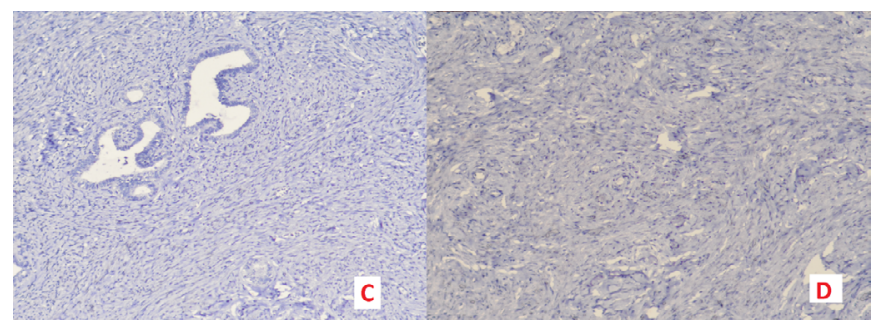

Figura 3. Marcadores estromais. A) Imunoexpressão de vimentina (100x); B) Imunoexpressão de alfa actina (100x); C) Imunoexpressão de desmina (100x).
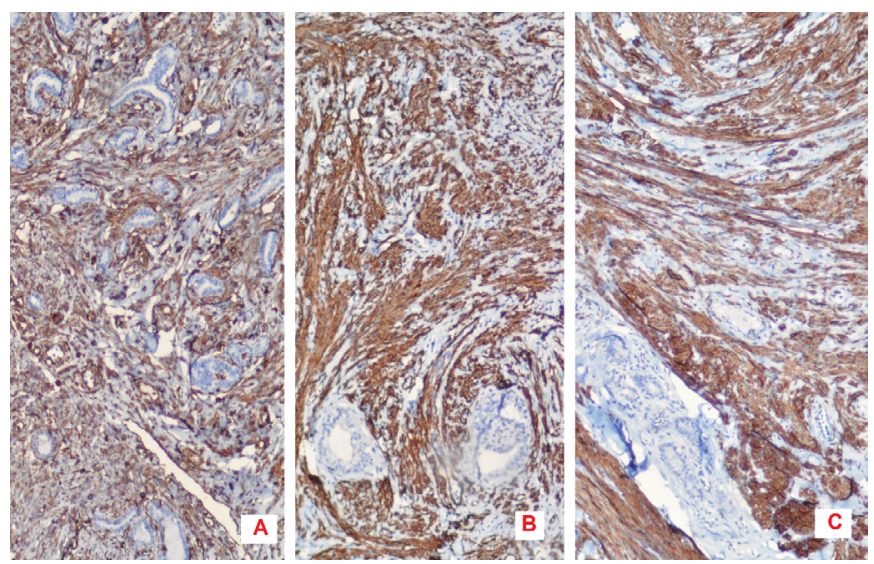

Figura 4. Receptores hormonais. A) Imunoexpressão de RE (100x); B) Imunoexpressão de RP (100x).

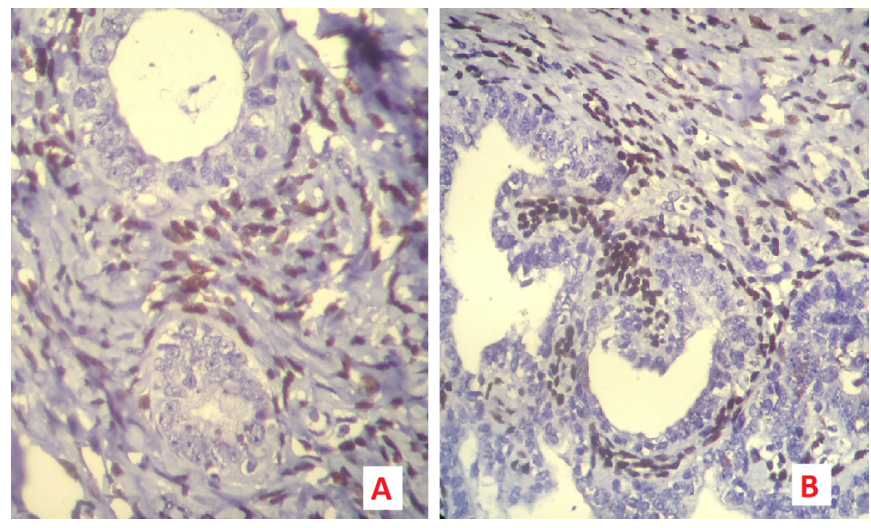

\section{DISCUSSÃO}

A característica principal do tumor epitelial e estromal misto do rim é seu padrão histológico bifásico, em que se observam elementos epiteliais, exibindo geralmente um componente cístico, recoberto por epitélio cuboidal e elementos estromais, representados por células fusiformes, variando desde um estroma hialinizado, até um estroma semelhante ao ovariano. ${ }^{1}$
No caso apresentado esse padrão bifásico era evidente, sendo observados túbulos e cistos maiores, recobertos por epitélio cuboidal a colunar, por vezes com aspecto em hobnail, em meio a estroma de células fusiformes, aprisionando os elementos epiteliais e formando nódulos, lembrando o aspecto histológico dos fibroadenomas mamários.

O perfil imuno-histoquímico é variável e costuma mostrar imunopositividade nos componentes epiteliais com anticorpos para citoceratinas, especialmente a CK 7 e antígeno epitelial de membrana (EMA); já o componente estromal expressa vimentina, actina de músculo liso, caldesmon e desmina. ${ }^{7}$ Há uma alta frequência de positividade para receptores hormonais presentes nos núcleos das células fusiformes. ${ }^{9}$ A expressão de receptor de progesterona (RP), costuma ser mais extensa e marcar em um maior número de células, quando comparado ao receptor de estrógeno (RE). ${ }^{7}$ Em nosso caso, as marcações de imuno-histoquímica vão ao encontro do que está relatado na literatura vigente, inclusive a marcação para receptores hormonais (RE e RP).

A patogênese do MESTK ainda é desconhecida. A maioria dos casos é benigna, mas também são relatados casos de transformação maligna. ${ }^{10}$ As mulheres, sobretudo as de meia idade, são as mais afetadas e este tumor está muito relacionado à terapia de reposição hormonal, sugerindo que o estrógeno possa ter algum papel na patologia deste tumor. ${ }^{8}$ A paciente em questão estava na faixa etária de meia idade, mas não tinha história de terapia de reposição hormonal.

Os sintomas típicos do MESTK incluem hematúria, dor em flanco e massa palpável, no entanto, há muitos casos relatados de indivíduos assintomáticos, cuja neoplasia é descoberta incidentalmente por exames de imagem. ${ }^{9}$ A paciente apresentou sintomas urinários obstrutivos, decorrentes de cálculo coraliforme situado em rim direito, o que levou a realização de tomografia que comprovou a existência do cálculo e evidenciou uma lesão cística no rim contralateral.

Radiograficamente, o MESTK se apresenta na tomografia computadorizada como massa cística multilocular, com ocasionais calcificações, em geral classificados nas categorias Bosniak III, cujas lesões tem uma chance de 30 a $100 \%$ de serem malignas, e a cirurgia é recomendada, ou Bosniak IV, cuja cirurgia é fortemente indicada por tratar-se de lesão maligna até que se prove o contrário. ${ }^{11} \mathrm{~A}$ core-biopsy não é indicada para massas renais císticas, a menos que áreas sólidas estejam presentes. A cirurgia é recomendada na maioria dos casos de MESTK. ${ }^{7}$

Embora a maioria dos tumores epiteliais e estromais mistos do rim sejam benignos e tenham bom prognóstico, o manejo deve seguir os protocolos dos carcinomas de células renais. A nefrectomia é realizada na maioria dos casos, e os pacientes são acompanhados. Não há protocolos de tratamento quimio ou radioterápico relatado na literatura. ${ }^{7}$ A paciente do relato foi submetida a nefrectomia esquerda e o seguimento clínico não mostrou recorrência após um ano. 


\section{REFERÊNCIAS}

1. Caliò A, Eble JN, Grignon DJ, Delahunt B. Mixed epithelial and stromal tumor of the kidney: a clinicopathologic study of 53 cases. Am J Surg Pathol. 2016;40(11):1538-49.

2. Block NL, Grabstald HG, Melamed MR. Congenital mesoblastic nephroma (leiomyo $\neg$ matous hamartoma): first adult case. J Urol. 1973;110(4):380-3.

3. Michal M, Syrucek M. Benign mixed epithelial and stromal tumor of the kidney. Pathol Res Pract. 1998;194(6):445-8.

4. Pêgas KL, Cambruzzi E, Furian RD, Hartmann AA, Lamonatto SE, Zanatta JM, et al. Renal mixed epithelial and stromal tumor: case report. J Bras Patol Med Lab. 2015;51(1):39-43.

5. Cheng Yang, Jianzhong Wang, Hexi Du, Mingwei Chen, Xia Zhu, Jun Zhou, et al. Mixed epithelial and stromal tumor of the kidney: a rare case report and review of the literatures. Int J Clin Exp Med. 2015;8(8):14180-3.

6. Greco F, Faiella E, Santucci D, De Lisi D, Lo Vullo G, Zobel BB, et al. Ultrasound imaging of cystic nephroma. J Kidney Cancer VHL. 2017;4(3):1-9.
7. Moslemi MK. Mixed epithelial and stromal tumor of the kidney or adult mesoblastic nephroma: an update. Urol J. 2010;7(3):141-7.

8. Wang Y, Yuan J, Wang J, Fu Q. Mixed epithelial and stromal tumor of the kidney: report of a rare case and review of literature. Int J Clin Exp Pathol. 2015;8(9):11772-7.

9. Wang CJ, Lin YW, Xiang H, Fang DB, Jiang P, Shen BH. Mixed epithelial and stromal tumor of the kidney: report of eight cases and literature review. World J Surg Oncol. 2013;11:207.

10. Suzuki T, Hiragata S, Hosaka K, Oyama T, Kuroda N, Hes O, et al. Malignant mixed epithelial and stromal tumor of the kidney: report of the first male case. Int J Urol. 2013;20(4):448-50.

11. Tsai SH, Wang JH, Lai YC, Chang YH, Chung HJ, Chang LS. Clinical-radiologic correlation of mixed epithelial and stromal tumor of the kidneys: cases analysis. Journal of the Chinese Medical Association. $2016 ; 79: 554 \mathrm{e} 558$.

\section{Como citar:}

Barbosa FF, Oliveira AR, Souza ET, Hirth CG. Tumor epitelial e estromal misto do rim: relato de caso. Rev Med UFC. 2019 jul-set;59(3):65-68. 